\title{
Neurolytic celiac plexus block enhances skeletal muscle insulin signaling and attenuates insulin resistance in GK rats
}

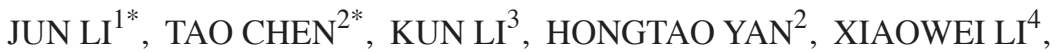 \\ YUN YANG $^{3}$, YULAN ZHANG ${ }^{1}$, BINGYIN SU $^{5}$ and FUXIANG LI ${ }^{6}$ \\ ${ }^{1}$ Department of Anesthesiology; ${ }^{2}$ General Surgery Center; ${ }^{3}$ Medical Laboratory Center; and ${ }^{4}$ Department of Urology, \\ Chengdu Military General Hospital; ${ }^{5}$ Development and Regeneration Key Laboratory of Sichuan, Chengdu Medical College; \\ ${ }^{6}$ Department of ICU, Chengdu Military General Hospital, Chengdu, Sichuan 610083, P.R. China
}

Received November 14, 2014; Accepted December 4, 2015

DOI: $10.3892 /$ etm.2016.3087

\begin{abstract}
Non-insulin-dependent diabetes mellitus (NIDDM) is associated with chronic inflammatory activity and disrupted insulin signaling, leading to insulin resistance (IR). The present study investigated the benefits of neurolytic celiac plexus block (NCPB) on IR in a rat NIDDM model. Goto-Kakizaki rats fed a high-fat, high-glucose diet to induce signs of NIDDM were randomly divided into NCPB and control groups; these received daily bilateral $0.5 \%$ lidocaine or $0.9 \%$ saline injections into the celiac plexus, respectively. Following 14 and 28 daily injections, rats were subject to oral glucose tolerance tests (OGTTs) or sacrificed for the analysis of serum free fatty acids (FFAs), serum inflammatory cytokines and skeletal muscle insulin signaling. Compared with controls, rats in the NCPB group demonstrated significantly $(\mathrm{P}<0.05)$ lower baseline, 60-min and 120-min OGTT values, lower 120-min serum insulin, lower IR [higher insulin sensitivity index ( $\left.\mathrm{ISI}_{1}\right)$ and lower $\mathrm{ISI}_{2}$ ) and lower serum FFAs, tumor necrosis factor- $\alpha$, interleukin (IL)-1 $\beta$ and IL-6. Conversely, NCPB rats exhibited higher basal and insulin-stimulated skeletal muscle glucose uptake and higher skeletal muscle insulin receptor substrate-1 (IRS-1) and glucose transporter type 4 expression. There were no differences between the groups in insulin receptor $\beta(R \beta)$ or Akt expression; however R $\beta$-Y1162/Y1163 and Akt-S473 phosphorylation levels were higher and IRS-1-S307 phosphorylation were lower in NCPB rats than in the controls.
\end{abstract}

Correspondence to: Dr Bingyin Su, Development and Regeneration Key Laboratory of Sichuan, Chengdu Medical College, 601 Rongdu Avenue, Chengdu, Sichuan 610083, P.R. China E-mail: subingy@126.com

Dr Fuxiang Li, Department of ICU, Chengdu Military General Hospital, 270 Rongdu Avenue, Chengdu, Sichuan 610083, P.R. China E-mail: lifuxiang98@163.com

${ }^{*}$ Contributed equally

Key words: neurolytic celiac plexus block, Goto-Kakizaki rats, insulin resistance, insulin signal transduction pathway
These results indicate that NCPB improved insulin signaling and reduced IR, possibly by inhibiting inflammatory cytokine release.

\section{Introduction}

Non-insulin-dependent diabetes mellitus (NIDDM or type $2 \mathrm{DM}$ ), the predominant form of adult-onset DM, is rapidly becoming a global public health emergency (1). Insulin resistance (IR) and pancreatic islet cell dysfunction are the major pathophysiological characteristics of the disease, leading to relative insulin deficiency and aberrant glucose metabolism (2). The development of IR is closely associated with inflammatory processes, and NIDDM is increasingly recognized as an inflammatory metabolic disorder. In NIDDM, the chronic elevation of inflammatory cytokines and free fatty acids (FFAs) disrupts insulin signaling and, ultimately, causes the degeneration of pancreatic cells (3-6). The insulin receptor (InsR)/insulin receptor substrate (IRS)/phosphoinositide 3-kinase (PI3K)/Akt pathway is the critical homeostatic cascade linking insulin release to tissue glucose uptake (7). Increasing evidence suggests that this pathway is a target of multiple metabolic signals and inflammatory cytokines associated with obesity $(8,9)$. This pathway is also considered to represent a key risk factor in the development of NIDDM, including its actions upon FFAs, tumor necrosis factor $\alpha(\mathrm{TNF}-\alpha)$ and the pro-inflammatory interleukins IL-1 $\beta$ and IL-6 (10-12). Amongst other effects, these factors cause aberrant phosphorylation and dephosphorylation of InsR, IRS and Akt; this reduces the efficacy of insulin signaling, including insulin-evoked glucose transport $(4,6,7,10,11)$.

The celiac plexus is the body's largest autonomic nerve plexus; neurolytic celiac plexus block (NCPB) is therefore an effective method to relieve pain, for instance in cancer treatments (13). Our previous study of NCPB in rats following resection of $70 \%$ of the liver indicated that NCPB attenuated IR; this may be due to an inhibition of systemic inflammatory response syndrome that typically occurs following severe trauma (14). NCPB may therefore slow or reverse NIDDM-associated dysfunction via the suppression of immune-mediated IR. The current study therefore measured functional and molecular changes associated with NIDDM, 
including oral glucose tolerance tests (OGTTs), insulin sensitivity, skeletal muscle glucose uptake, serum cytokines and skeletal muscle insulin signaling in the Goto-Kakizaki (GK) rat model of diabetes $(15,16)$.

\section{Materials and methods}

Chemicals and reagents. Rat enzyme-linked immunosorbent assay (ELISA) kits for measurement of FFAs, TNF- $\alpha, \mathrm{IL}-1 \beta$ and IL-6 were purchased from Cusabio Biotech Co., Ltd. (Wuhan, China). Insulin radioimmunoassay kit purchased from Tianjin Jiuding Medical Biology Engineering Co. (Tianjin, China). Tissue protein extraction solution was purchased from Pierce Biotechnology,Inc.(Rockford,IL,USA). The following primary antibodies were purchased from Santa Cruz Biotechnology, Inc. (Dallas, TX, USA): Anti-glyceraldehyde-3-phosphate dehydrogenase (GAPDH) mouse monoclonal immunoglobulin G (IgG; cat. no. sc-166574), anti-insulin receptor $\beta$ $(\mathrm{R} \beta)$ rabbit polyclonal IgG (cat. no. sc-711), anti-p-insulin R $\beta$ antibody (Tyr 1162/1163; cat. no. sc-25103), anti-insulin receptor substrate-1 (IRS-1) rabbit polyclonal IgG (cat. no. sc-559), anti-p-IRS-1 (S307) rabbit polyclonal IgG (cat. no. sc-33956), anti-Akt1/2/3 rabbit polyclonal IgG (cat. no. sc-8312), anti-p-Akt1/2/3 (S473) rabbit polyclonal IgG (cat. no. sc-7985-R), anti-glucose transporter type 4 (GLUT4) rabbit polyclonal IgG (cat. no. sc-7938) and goat anti-p-insulin R $\beta$ (Y1162/Y1163; cat. no. sc-25103). Horseradish peroxidase (HRP)-labeled rabbit anti-mouse IgG (cat. no. TA130002), HRP-labeled rabbit anti-goat $\operatorname{IgG}$ (cat. no. TA130024), HRP-labeled goat anti-rabbit IgG (cat. no. TA130031) and enhanced chemiluminescence (ECL) detection reagents were from OriGene Technologies, Inc. (Beijing, China).

GK rat model of NIDDM. A total of 25, 3-month-old GK male rats (weighing $305.7 \pm 18.4 \mathrm{~g}$ ) were purchased from Shanghai SLAC Laboratory Animal Co., Ltd. (Shanghai, China). The animal experiments were approved by the Committee of Animal Care and Use within the of Chengdu Military General Hospital Command Area (Chengdu, China). Diabetes was induced using a high-fat and high-sugar diet, as previously described (17). After the first 2 weeks of the diet, fasting blood glucose (FBG) was tested weekly after an 18-h fast, using blood from the tail vein. A FBG level of $>9 \mathrm{mmol} / \mathrm{l}$ was considered to indicate NIDDM. All 25 rats demonstrated tail vein $\mathrm{FBG}$ values $>9 \mathrm{mmol} / \mathrm{l}$ at the first test.

Baseline OGTT and insulin sensitivity indices $\left(\mathrm{ISI}_{1}\right.$ and $\mathrm{ISI}_{2}$ ) were recorded in 5 NIDDM rats (N0), and the remainder were randomly divided into two groups. The NCPB group received daily bilateral percutaneous injections of $0.5 \%$ lidocaine ( $1 \mathrm{ml} / \mathrm{side})$ and control group rats received the same volume of $0.9 \%$ saline into the celiac plexus. Following the 14th (N14) and 28th (N28) injections, OGTT, IR, serum cytokine levels and the expression and phosphorylation status of insulin signaling factors in skeletal muscles were measured in 5 rats from each group.

Neurolytic celiac plexus block. Rats received $0.5 \%$ lidocaine ( $2 \mathrm{ml}$ once/day) or saline under ether anesthesia. The puncture point was determined in accordance with a previous report (18). Briefly, rats were injected bilaterally at the first lumbar transverse process, the first bony protrusion under the root of the last rib. The needle was inserted vertically until it touched the tip of the transverse process, and was then turned medially and $70-80^{\circ}$ vertically over the outer edge of the transverse process tip. Insertion continued until penetration was felt.

OGTT assay. Rats were administered $500 \mathrm{~g} / \mathrm{l}$ glucose at $2 \mathrm{~g} / \mathrm{kg}$ body mass by gavage, under ether anesthesia and following an 18-h fast. Blood samples $(0.5 \mathrm{ml})$ from the orbital venous plexus were obtained at $\mathrm{T}_{0}(0 \mathrm{~min}), \mathrm{T}_{1}(60 \mathrm{~min})$ and $\mathrm{T}_{2}(120 \mathrm{~min})$. Blood glucose was measured by the glucose oxidase method (19) and serum insulin by radioimmunoassay using the insulin radioimmunoassay kit according to the manufacturer's protocol. Blood glucose at $\mathrm{T}_{0}$ was considered to be the FBG and $\mathrm{T}_{0}$ insulin as fasting insulin (FIns). OGTT values were used to calculate the insulin sensitivity indices (ISI ${ }_{1}$ and $\mathrm{ISI}_{2}$ ) as previously described $(13,20):$ ISI $_{1}=1 /(\mathrm{FBG} x \mathrm{FIns})$ and $\mathrm{ISI}_{2}=$ areaunder the curve of glucose (AUCg)/area under the insulin curve (AUCi), where AUCi $=\left[\left(\mathrm{I}_{0 \text { min }}+\mathrm{I}_{60 \text { min }}\right) / 2\right]+\left[\left(\mathrm{I}_{60 \text { min }}+\mathrm{I}_{120 \mathrm{~min}}\right) / 2\right]$ and $\operatorname{AUCg}=\left[\left(\mathrm{G}_{0 \min }+\mathrm{G}_{60 \mathrm{~min}}\right) / 2\right]+\left[\left(\mathrm{G}_{60 \mathrm{~min}}+\mathrm{G}_{120 \mathrm{~min}}\right) / 2\right]$.

Determination of skeletal muscle glucose uptake. Rats were sacrificed by decapitation $12 \mathrm{~h}$ after the OGTT test. Serum and quadriceps muscle samples for biochemical analyses were collected, which were stored at $-80^{\circ} \mathrm{C}$ until use. A $100 \mathrm{mg}$ sample of freshly isolated soleus muscle was used to determine skeletal muscle 2-deoxy-D-glucose (2-DG) uptake in each rat (14). Soleus muscle bundles were placed in Krebs-Ringer bicarbonate buffer (OriGene Technologies, Inc., Beijing, China) with or without $1.0 \mu \mathrm{mol} / \mathrm{ml}$ insulin to measure insulin-stimulated and basal glucose uptake, respectively. After $1 \mathrm{~h}$ shaking at $37^{\circ} \mathrm{C}$ under $95 \% \mathrm{O}_{2}$ and $5 \% \mathrm{CO}_{2}, 1.85 \times 10^{4} \mathrm{~Bq}{ }^{3} \mathrm{H}-2-\mathrm{DG}$ and $1.5 \mathrm{nmol} / \mathrm{l}$ 2-DG (Serva Electrophoresis $\mathrm{GmbH}$, Heidelberg, Germany) were added and incubation continued with shaking for $30 \mathrm{~min}$. Muscle samples were washed and placed in liquid scintillation vials with ethylene glycol ether $(5 \mathrm{ml})$ and scintillation fluid ( $0.5 \mathrm{~g}$ 2,5-diphenyloxazole, $0.2 \mathrm{~g}$ phenylene benzoxazole and $1,000 \mathrm{ml}$ toluene). Vials were left overnight in a darkroom. Other muscle samples were boiled prior to their use in assays, in order to correct for extracellular glucose uptake and non-specific absorption. Radioactivity was measured

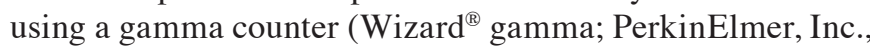
Waltham, MA, USA).

Serum cytokine detection. Serum samples collected prior to and following the 14th and 28th daily injections were used to detect serum levels of FFAs and the inflammatory cytokines TNF- $\alpha$, IL-1 $\beta$ and IL-6, using commercial ELISA kits in accordance with the manufacturers' instructions.

Western blotting. Skeletal muscle total protein was extracted in protein extraction solution in accordance with the manufacturer's instructions, and measured using the Bradford method. Extracted proteins were separated on $6 \%$ sodium dodecyl sulfate polyacrylamide gels at $50 \mu \mathrm{g}$ protein per lane, and transferred to polyvinylidene difluoride membranes using semi-dry electroblotting for $1 \mathrm{~h}$. The membranes were blocked in phosphate-buffered saline (PBS) containing $0.5 \%$ bovine 
A

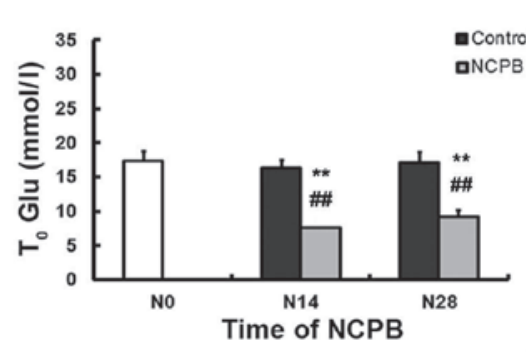

C

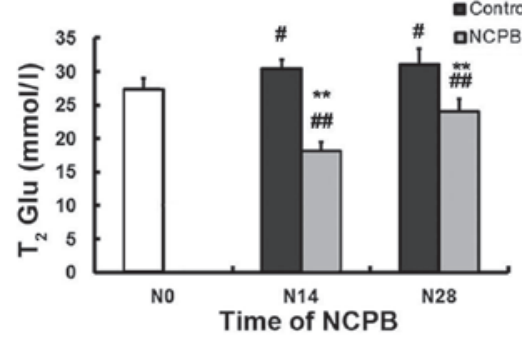

E

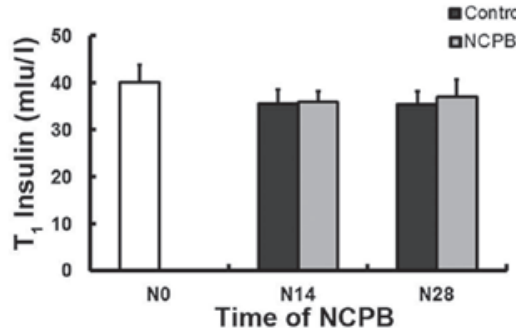

B

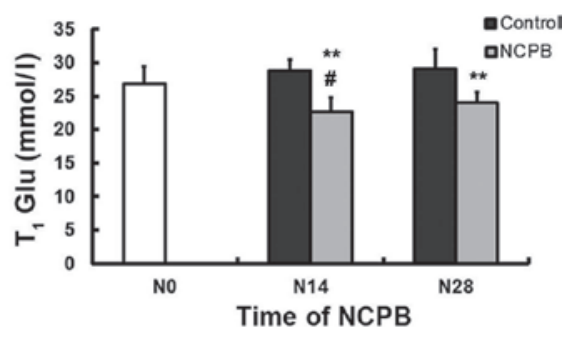

D

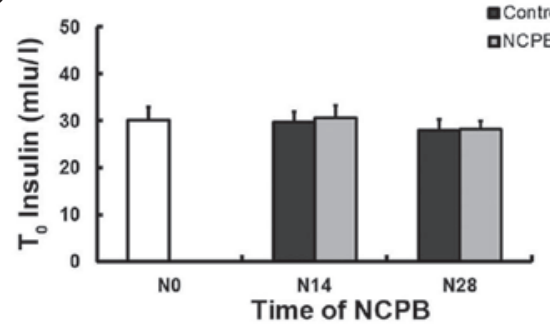

F

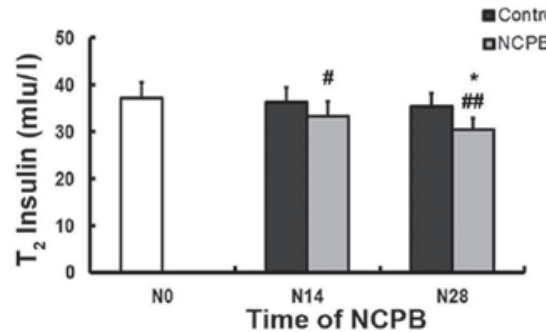

Figure 1. Daily neurolytic celiac plexus block enhances glucose tolerance in non-insulin-dependent diabetes mellitus model rats. The mean concentrations of blood glucose at (A) $\mathrm{T}_{0}$, (B) $\mathrm{T}_{1}$ and (C) $\mathrm{T}_{2}$, and serum insulin at (D) $\mathrm{T}_{0}$, (E) $\mathrm{T}_{1}$ and (F) $\mathrm{T}_{2}$, measured using an oral glucose tolerance test, in the control and NCPB groups. Data are expressed as the mean \pm standard deviation at each time point $(n=5) . T_{0}, 0$ min after glucose gavage; $T_{1}, 60$ min after glucose gavage; $\mathrm{T}_{2}, 120$ min after glucose gavage; N0, injection day $0 ; \mathrm{N} 14$, injection day 14 ; N28, injection day 28; T, time; Glu, blood glucose; NCPB, neurolytic celiac plexus block. ${ }^{\#} \mathrm{P}<0.05$ and ${ }^{\# \#} \mathrm{P}<0.01$ vs. N0; ${ }^{*} \mathrm{P}<0.05$ and ${ }^{* *} \mathrm{P}<0.01$ vs. control group.

serum albumin (OriGene Technologies, Inc.); membranes were then incubated overnight at $4^{\circ} \mathrm{C}$ in $0.01 \mathrm{~mol} / 1 \mathrm{PBS}$ containing an antibody against insulin $\mathrm{R} \beta$, IRS-1, Akt1/2/3, GLUT4, p-R $\beta$, p-IRS-1, p-Akt1/2/3 or GAPDH, the gel loading control. The immunolabeled membranes were washed 3 times, $5 \mathrm{~min} /$ wash, with $0.01 \mathrm{~mol} / 1 \mathrm{PBS}-0.02 \%$ Tween and then incubated with an HRP-labeled rabbit anti-mouse or HRP-labeled goat anti-rabbit secondary antibody, as appropriate (dilution, 1:400) for $1 \mathrm{~h}$ at $37^{\circ} \mathrm{C}$. Following treatment with ECL detection reagents, immunoblot images were acquired and the optical density (intensity) $\mathrm{x}$ area $\left(\mathrm{mm}^{2}\right)$ of the bands were measured using a UVP GelDoc 310 Imaging system (UVP, Inc., Upland, CA, USA). The relative target protein expression levels were estimated by the ratio of the optical density (intensity) $\mathrm{x}$ area $\left(\mathrm{mm}^{2}\right)$ of the target band and that of the GAPDH band.

Statistical analysis. Statistical analysis was performed using SPSS statistical software, version 17.0 (SPSS Inc., Chicago, IL, USA). Experimental data are presented as the mean \pm standard deviation. All data sets were tested for homogeneity of variance (probability of error of 5\%). Groups with homogeneity of variance were compared using an analysis of variance. When the heterogeneity of variance assumption was rejected, groups were compared using F-tests. $\mathrm{P}<0.05$ was considered to indicate a statistically significant difference.

\section{Results}

$N C P B$ decreases serum glucose levels in NIDDM rats. Indices of glucose tolerance, insulin sensitivity and skeletal muscle insulin signaling in NIDDM model rats treated by daily neurolytic celiac plexus block (NCPB) using $0.5 \%$ lidocaine, and control rats injected with saline were compared. Fasting OGTTs in NIDDM model rats $\left(\mathrm{T}_{0}\right)$ revealed significantly lower mean FBG levels in NCPB group rats following the 14th and 28th daily NCPB (N14 and N28) compared with the first measurement prior to NCPB (vs. N0; P<0.01; Fig. 1A). By contrast, control group rats demonstrated no reduction in $\mathrm{FBG}$ following the 14th and 28th daily saline injection compared with N0; furthermore, NCPB-treated rats reported significantly lower FBG compared with the control, saline-treated rats following $\mathrm{N} 14$ and $\mathrm{N} 28(\mathrm{P}<0.01$; Fig. 1A). NCPB group rats also demonstrated lower blood sugar levels subsequent to $\mathrm{N} 14$ at $\mathrm{T}_{1}(60 \mathrm{~min} ; \mathrm{P}<0.05 ;$ Fig. $1 \mathrm{~B})$, and subsequent to $\mathrm{N} 14$ and $\mathrm{N} 28$ at $\mathrm{T}_{2}$ (120 min; $\mathrm{P}<0.01$; Fig. 1C) following glucose gavage, compared with blood sugar readings at N0. NCPB-treated rats also reported lower blood sugar values compared with the control group following $\mathrm{N} 14$ and $\mathrm{N} 28$, at $\mathrm{T}_{1}$ and at $\mathrm{T}_{2}(\mathrm{P}<0.01$; Fig. 1B and $\mathrm{C}$ ); however, it is of note that at $\mathrm{T}_{2}$, control group blood glucose levels following N14 and N28 were significantly higher than those at N0 $(\mathrm{P}<0.05)$. Serum insulin levels at $\mathrm{T}_{0}$ and $\mathrm{T}_{1}$ were comparable amongst all groups (Fig. 1D and $\mathrm{E}$ ); 

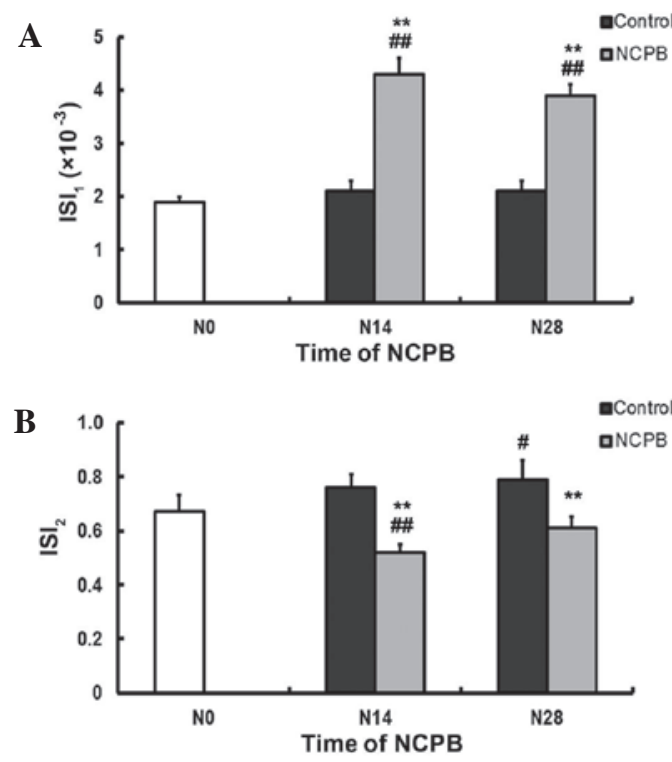

Figure 2. Differences in (A) ISI $_{1}$ and (B) ISI $_{2}$ between control and NCPB group rats. Data are expressed as the mean \pm standard deviation at each time point $(\mathrm{n}=5)$. $\mathrm{N} 0$, injection day 0 ; $\mathrm{N} 14$, injection day $14 ; \mathrm{N} 28$, injection day 28 ; $\mathrm{ISI}_{1}$, insulin sensitive index 1; $\mathrm{ISI}_{2}$, insulin sensitive index 2; NCPB, neurolytic celiac plexus block. ${ }^{\#} \mathrm{P}<0.05$ and ${ }^{\# \#} \mathrm{P}<0.01$ vs. $\mathrm{N} 0 ;{ }^{* *} \mathrm{P}<0.01$ vs. control group.

however, the serum insulin level at $\mathrm{T}_{2}$ was significantly lower than the baseline value $(\mathrm{N} 0)$ in $\mathrm{NCPB}$ rats $(\mathrm{P}<0.05$ following $\mathrm{N} 14 ; \mathrm{P}<0.01$ following N28) and lower than the control group value following $\mathrm{N} 28$ at $\mathrm{T}_{2}(\mathrm{P}<0.05$; Fig. $1 \mathrm{~F})$. It was therefore concluded that daily NCPB treatments enhanced glucose tolerance in NIDDM model rats.

$N C P B$ reduces $I R$. In the control group, the $\mathrm{ISI}_{1}$ values measured at N14 and N28 were not significantly different from that at N0. By contrast, the $\mathrm{ISI}_{1}$ values reported following N14 and N28 in the NCPB group were significantly higher than the ISI $I_{1}$ values at N0, and than the relevant control values $\left(\mathrm{P}<0.01\right.$; Fig. 2A). The $\mathrm{ISI}_{2}$ value of the control group at $\mathrm{N} 28$ was significantly higher than that at $\mathrm{N} 0(\mathrm{P}<0.05$; Fig. 2B). In the NCPB group, the $\mathrm{ISI}_{2}$ at $\mathrm{N} 14$ was significantly lower than that at $\mathrm{N} 0$, and significantly lower than the corresponding control group values following N14 and N28 ( $\mathrm{P}<0.01$; Fig. 2B).

$N C P B$ enhances baseline and insulin-stimulated glucose uptake in skeletal muscle. Basal glucose uptake by skeletal muscle in control group rats decreased between N0 and N14 $(\mathrm{P}<0.05)$ and more so following $\mathrm{N} 28(\mathrm{P}<0.01$; Fig. $3 \mathrm{~A})$. By contrast, basal glucose uptake was maintained in the NCPB group rats, revealing no significant change from the NO baseline but higher values following N14 and N28 compared with controls $(\mathrm{P}<0.01 ;$ Fig. $3 \mathrm{~A})$. Insulin-stimulated glucose uptake by skeletal muscle in the control group rats did not significantly change following N14, but was significantly lower than that at N0 by N28 (P<0.01; Fig. 3B). Insulin-stimulated glucose uptake by skeletal muscle from the NCPB group following N14 did not differ from baseline, but was significantly higher at $\mathrm{N} 28$ compared with that of the control group ( $\mathrm{P}<0.01 ;$ Fig. 3B).
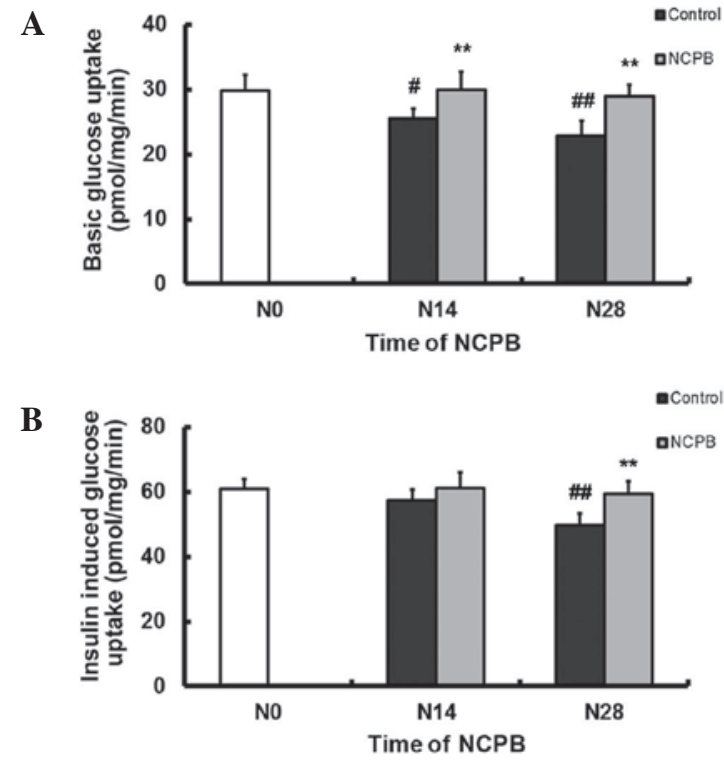

Figure 3. Differences in (A) basal glucose uptake and (B) insulin-stimulated glucose uptake by skeletal muscle in control and NCPB group rats. Data are expressed as the mean \pm standard deviation at each time point $(n=5)$. N0, injection day 0 ; N14, injection day 14 ; N28, injection day 28 ; NCPB, neurolytic celiac plexus block. ${ }^{\#} \mathrm{P}<0.05$ and ${ }^{\# \prime} \mathrm{P}<0.01$ vs. $\mathrm{N} 0 ;{ }^{* *} \mathrm{P}<0.01$ vs. control group.

NCPB reduces serum FFA and pro-inflammatory cytokine levels. In the control group, serum TNF- $\alpha$ levels were significantly higher at N14 and N28 compared with the N0, baseline level $(\mathrm{P}<0.05$ and $\mathrm{P}<0.01$, respectively; Fig $4 \mathrm{~A})$. There was no significant change in serum TNF- $\alpha$ in the NCPB group following N14 and N28 compared with the levels at N0; however, N14 and N28 TNF- $\alpha$ levels were significantly lower than the corresponding control group values $(\mathrm{P}<0.05$ and $\mathrm{P}<0.01$, respectively; Fig. 4A). Similarly, serum IL-1 $\beta$ levels increased in the control group compared with the NO baseline levels $(\mathrm{P}<0.05$ at $\mathrm{N} 14 ; \mathrm{P}<0.01$ at $\mathrm{N} 28)$, but decreased in the NCPB group $(\mathrm{P}<0.01$ following N14 and N28 compared with the N0 levels); furthermore, NCPB group values were significantly lower than corresponding control values $(\mathrm{P}<0.01$; Fig. 4B). Serum IL-6 levels did not change in the control group during 28 days of saline injections, but were lower in the NCPB group compared with the N0 baseline levels $(\mathrm{P}<0.05$ at $\mathrm{N} 14 ; \mathrm{P}<0.01$ at $\mathrm{N} 28)$ and with the corresponding control group values $(\mathrm{P}<0.05$ and $\mathrm{P}<0.01$, respectively; Fig. $4 \mathrm{C})$. Control group rats demonstrated significantly elevated serum FFA levels following N14 and N28 compared with N0 levels $(\mathrm{P}<0.05$ and $\mathrm{P}<0.01$, respectively; Fig. 4D). By contrast, serum FFA levels in the NCPB group gradually decreased and were significantly lower than the N0 baseline values following N28 $(\mathrm{P}<0.01$; Fig. 4D). Following N14 and N28, serum FFA levels were significantly lower in the NCPB group compared with the respective control group values $(\mathrm{P}<0.01$; Fig. 4D).

Expression and activation of insulin signaling factors in skeletal muscle. Expression of insulin $\mathrm{R} \beta$ in skeletal muscle did not differ significantly from N0 levels in the NCPB or control groups following N14 and N28 (Fig. 5A and B). However, $R \beta$ tyrosine 1162 and 1163 dual phosphorylation, which is required for receptor autophosphorylation and 


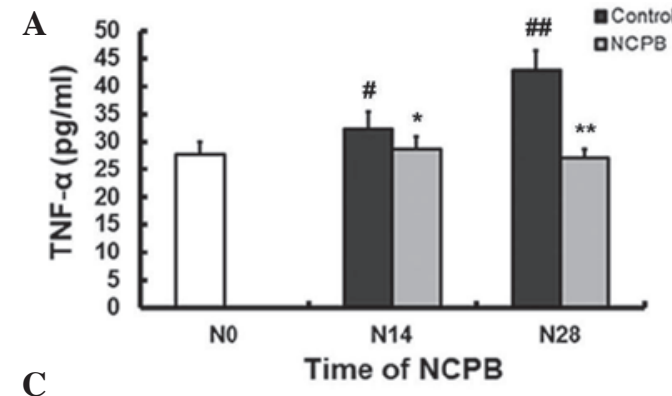

C

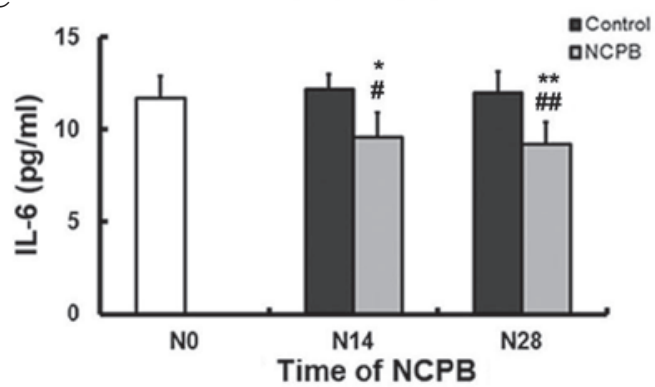

B
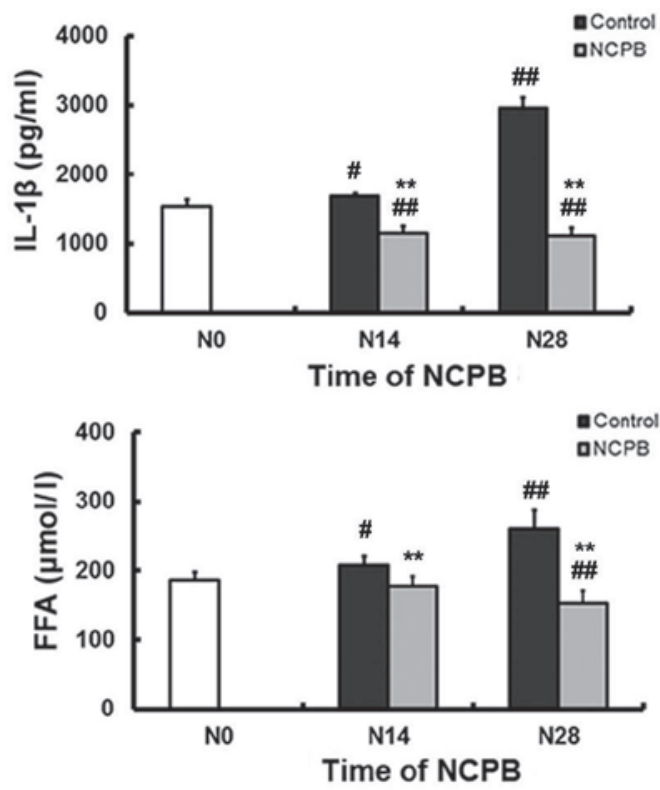

Figure 4. Serum concentrations of (A) TNF- $\alpha$, (B) IL-1 $\beta$, (C) IL-6, and (D) FFAs in control and NCPB group rats. Data are expressed as the mean \pm standard deviation at each time point $(n=5)$. N0, injection day $0 ; \mathrm{N} 14$, injection day $14 ; \mathrm{N} 28$, injection day 28 ; NCPB, neurolytic celiac plexus block; TNF- $\alpha$, tumor necrosis factor- $\alpha$; IL, interleukin; FFAs, free fatty acids. ${ }^{\#} \mathrm{P}<0.05$ and ${ }^{\# \#} \mathrm{P}<0.01$ vs. N0; ${ }^{*} \mathrm{P}<0.05$ and ${ }^{* *} \mathrm{P}<0.01$ vs. control group.

insulin-induced signaling, including glucose uptake $(21,22)$, was significantly lower following N14 and N28 in the control group compared with N0 levels $(\mathrm{P}<0.01$; Fig. 5A and $\mathrm{C})$. In the NCPB group, phosphorylated tyrosine 1162 and 1163 levels did not significantly decrease until N28 ( P<0.01), and N14 and N28 expression levels were significantly higher than those of the control group at $\mathrm{N} 14$ and $\mathrm{N} 28$ ( $\mathrm{P}<0.01$; Fig. 5A and $\mathrm{C})$. Expression of IRS-1, a key adaptor protein in transmission of signals from insulin receptors to Akt and other kinases (23), did not differ from baseline levels in skeletal muscle from control rats following N14 or N28, but increased significantly in skeletal muscle from the NCPB group compared with baseline and control levels ( $\mathrm{P}<0.01$; (Fig. 5A and D). Phosphorylation of IRS-1 serine 307, a post-translational modification associated with insulin resistance (24), was unchanged at N14 and N28 relative to the baseline levels in skeletal muscle from control rats, but decreased significantly at the two time points in the NCPB group compared with baseline levels $(\mathrm{P}<0.01)$ and with the corresponding levels observed in the control group $(\mathrm{P}<0.01$; Fig. 5A and E). Expression of Akt in skeletal muscle did not differ from baseline values in either group (Fig. 5A and F), but Akt serine 473 phosphorylation was significantly reduced compared with baseline levels in control and NCPB groups following N14 and N28 (P<0.0; Fig. 5A and F). However, expression was significantly higher in the NCPB group compared with the control group at N14 $(\mathrm{P}<0.01)$ and at N28 $(\mathrm{P}<0.05$; Fig. 5A and G). Finally, skeletal muscle expression of GLUT4 was significantly reduced following N14 and N28 in the control group $(\mathrm{P}<0.01)$, but significantly increased in the NCPB group following N28 ( $\mathrm{P}<0.05$; Fig. 5A and H). GLUT4 expression in the NCPB group was also significantly higher than that in the control group following N14 and N28 $(\mathrm{P}<0.01)$ (Fig. 5A and H). NCPB therefore partially or completely reversed numerous alterations to insulin signaling associated with IR and NIDDM.

\section{Discussion}

In the present study, GK rats fed a high-fat and high-sugar diet demonstrated several physiological deficits and molecular changes consistent with NIDDM, including elevated FBG levels, impaired glucose clearance, IR, reduced skeletal muscle glucose uptake and reduced expression levels of GLUT4 in skeletal muscle. In addition, dual Y1162/Y1163 phosphorylation of insulin receptor $\beta$ and Akt S473 phosphorylation were reduced. Finally, this model of NIDDM was associated with elevated serum FFA and inflammatory cytokine levels. Chronic NCPB, generated by the daily injection of $0.5 \%$ lidocaine, completely or partially attenuated these changes, which suggests that NCPB may mitigate a number of the pathophysiological deficits of NIDDM, such as IR, by reducing inflammatory damage.

IR is a critical pathogenic mechanism leading to the development of NIDDM. Development of IR involves changes to insulin receptor expression, and to downstream signaling pathways $(25,26)$. The insulin receptor is a multifunctional transmembrane glycoprotein consisting of an $\alpha$ subunit and a $\beta$ subunit. The $\alpha$ subunit is responsible for binding insulin, whilst the $\beta$ subunit has intrinsic tyrosine protein kinase (TPK) activity that initiates downstream intracellular signaling events (27). Numerous studies have demonstrated that diabetic hyperglycemia is associated with aberrant insulin receptor phosphorylation and reduced TPK activity $(28,29)$. In the present GK model, insulin R $\beta$ dual tyrosine 1162 and 1163 phosphorylation was markedly reduced. As Y1162/Y1163 dual phosphorylation is required for TPK autophosphorylation and activation, this reduction is likely to lead to decreased insulin signaling, which is indicative of insulin resistance. This IR-associated change was partially reversed by NCPB, as suggested by the OGTT results, consistent with partial attenuation of IR. 
A

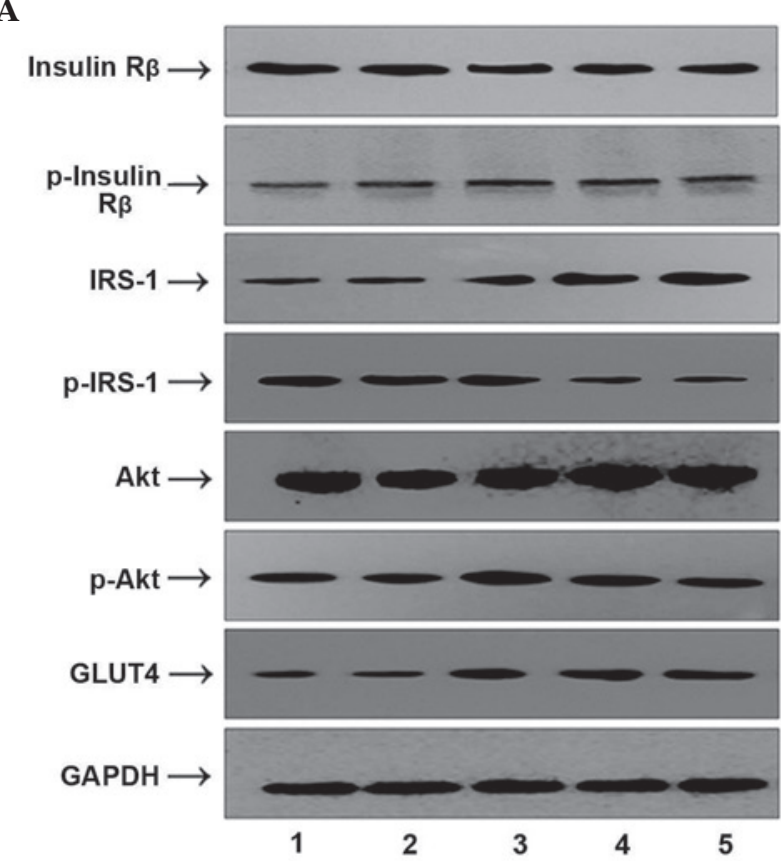

$\mathbf{E}$
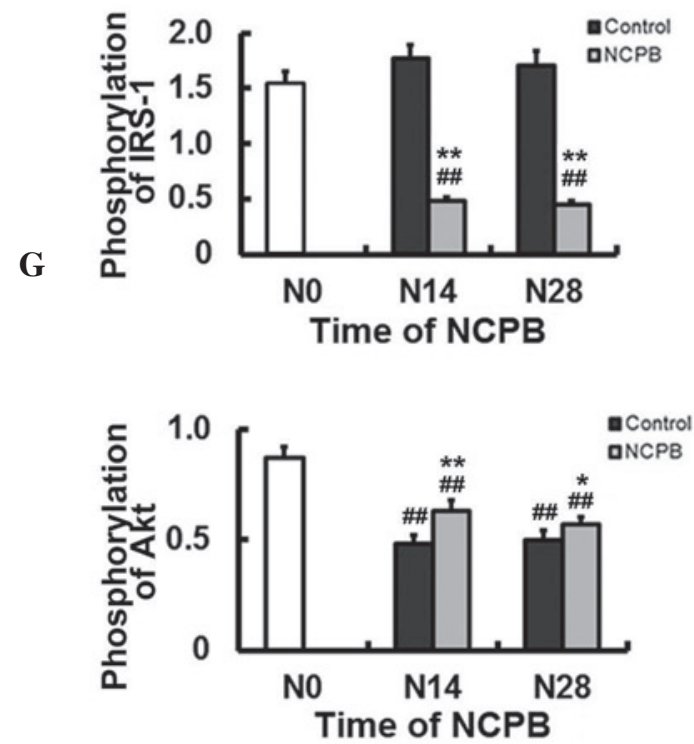

B

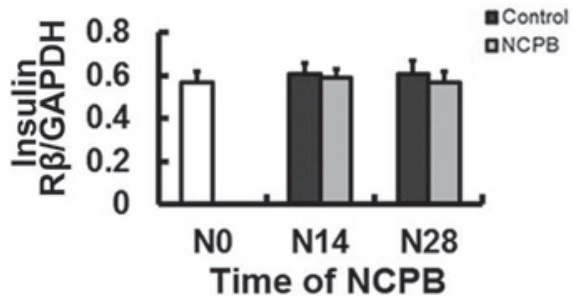

C
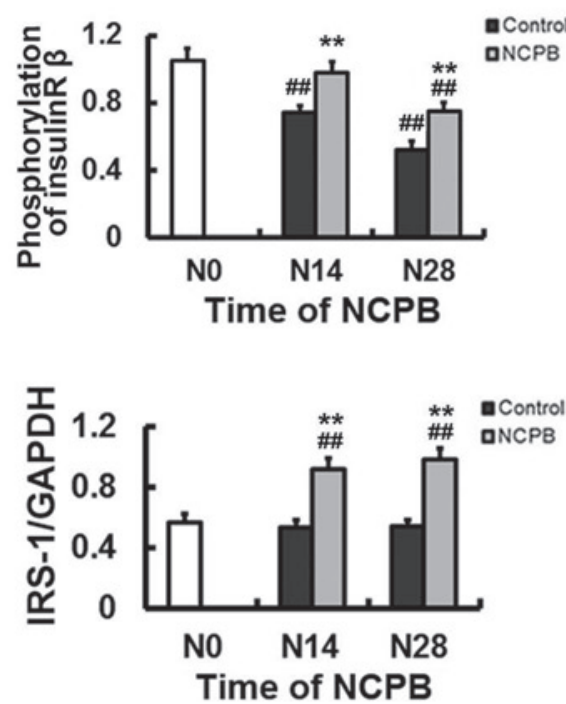

$\mathbf{H}$
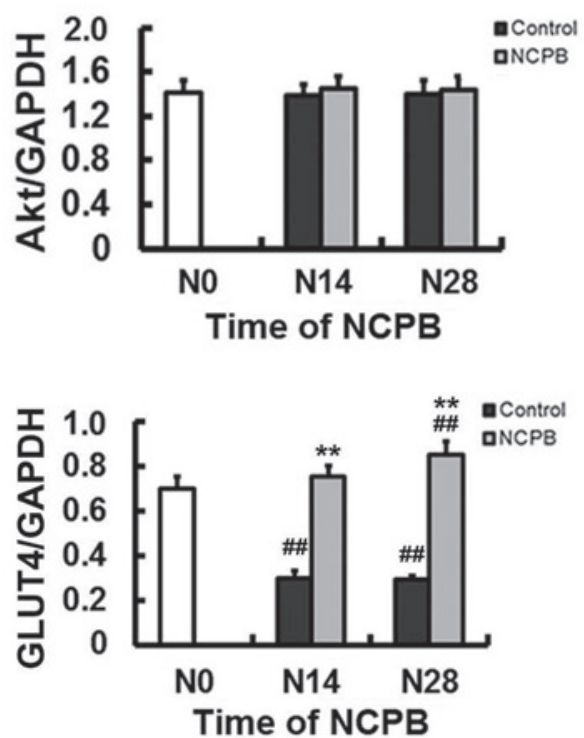

Figure 5. Protein expression and phosphorylation levels of muscular insulin R $\beta$, IRS-1, Akt and GLUT4 in control and NCPB group rats. (A) Lanes 1 and 2 , protein expression or phosphorylation level in the control group at N28 and N14, respectively. Lane 3, protein expression or phosphorylation level at N0. Lanes 4 and 5, protein expression or phosphorylation level in the NCPB group at N14 and N28, respectively. (B-H) Densitometric analyses (target protein optical density/GAPDH optical density). (B) Insulin R $\beta$, (C) pY1162/pY1163 insulin R $\beta$, (D) IRS-1, (E) pS307 IRS-1, (F) Akt, (G) pS473 Akt and (H) GLUT4. $\mathrm{N}$, injection day 0 ; N14, injection day 14; N28, injection day 28; IRS-1, insulin receptor substrate-1; GLUT4, glucose transporter type 4; GAPDH, glyceraldehyde-3-phosphate dehydrogenase; NCPB, neurolytic celiac plexus block. ${ }^{\# \#} \mathrm{P}<0.01$ vs. N0; $\mathrm{P}<0.05$ and ${ }^{* *} \mathrm{P}<0.01$ vs. control group.

IRS-1 is an important mediator of insulin signaling (30). Insulin R $\beta$ Y1162/Y1163 dual phosphorylation in the NCPB group was lower than baseline levels, which suggests only partial attenuation of IR, but daily NCPB significantly increased IRS-1 expression in skeletal muscle; this may compensate for the reduced insulin $\mathrm{R} \beta$ phosphorylation and thereby maintain skeletal muscle insulin signaling. Furthermore, insulin-triggered glucose uptake was maintained in NCPB-treated rats but lower than baseline values were reported in control group rats. Tyrosine residues 465, 612, 632, 662, 941 and 989 are the major IRS-1 tyrosine sites and are crucial regulatory sites for insulin signaling (31). Inflammatory cytokines hinder IRS tyrosine phosphorylation by activating serine-threonine kinases that, in turn, phosphorylate IRS-1 on residues, impeding interaction with insulin receptors and thereby reducing downstream signaling. TNF- $\alpha$ may also 
induce the phosphorylation of IRS-1 at serine $307(32,33)$. Phosphorylation of skeletal muscle IRS-1 at serine 307 was significantly reduced following NCPB treatments, indicating that attenuated IR achieved using NCPB may be associated with the decreased phosphorylation of IRS-1 serine 307.

Akt is a serine/threonine protein kinase and downstream target of PI3K (34). Under the action of insulin, PI3K activation produces phosphatidylinositol 3,4-bisphosphate and phosphatidylinositol 3,4,5-trisphosphate, which promote phosphoinositide-dependent kinase-1-mediated phosphorylation, activating Akt (35). Akt has two phosphorylation sites, serine 473 and threonine 308, and Akt is completely activated only when the two sites are phosphorylated (36). NCPB treatment did not affect Akt expression levels, but did partially reverse the reduced phosphorylation at serine 473 in control GK rats. Phosphorylated Akt may regulate insulin metabolism by controlling GLUT translocation (37) and NCPB may therefore maintain skeletal muscle glucose uptake by sustaining Akt activity. As a polar molecule, glucose must be transported into cells across the cell membrane by GLUTs in the majority of tissues, with the exception of cells in the small intestine and the renal tubules $(38,39)$. GLUT4 is an insulin-dependent glucose transporter that is only expressed in insulin-sensitive tissues, such as skeletal muscle, cardiac muscle and adipose tissue. GLUT4-mediated glucose transport is the rate-limiting step in glucose utilization in peripheral tissues such as fat and muscle. Reduced expression or translocation of GLUT4 impairs glucose utilization in peripheral tissues, thereby causing IR (40). In the adipocytes of patients with NIDDM and obese individuals, GLUT4 expression is significantly reduced (41) and, whilst total skeletal muscle GLUT4 expression is normal, defects occur in GLUT4 translocation to the membrane (42). In the current study, GLUT4 expression in skeletal muscle was significantly increased by NCPB, possibly by maintenance of Akt phospho-activation and sustained membrane translocation, which is consistent with maintenance of skeletal muscle glucose uptake and improved glucose clearance in NCPB-treated rats.

Inflammation is a central pathogenic mechanism in the development of IR and type 2 diabetes (43-46). Obesity, a key risk factor for NIDDM, is associated with chronic inflammation and the release of inflammatory mediators such as TNF- $\alpha$ from adipose tissue; these inflammatory components may subsequently reduce insulin signaling and insulin-evoked glucose uptake into skeletal muscle, and may also damage insulin-producing pancreatic $\beta$ cells $(3-6,11,12,43-46)$. As observed, TNF- $\alpha$ interferes with insulin receptor downstream signaling by phosphorylating IRS-1 at serine 307 , resulting in reduced PI3K/Akt activity and GLUT4 translocation $(32,33,47-49)$. In addition, TNF- $\alpha$ also directly inhibits GLUT4 mRNA expression (50-52). Furthermore, TNF- $\alpha$ directly inhibits adipocyte differentiation and accelerates the decomposition of fat, resulting in increased serum FFA levels $(53,54)$, which can cause IR by PKC- $\theta$-mediated IRS-1 serine 307 phosphorylation (55). TNF- $\alpha$ may also indirectly affect insulin signaling by stimulating the secretion of glucocorticoids, glucagon and catecholamines (56). In the present study, NCPB treatment reduced serum FFA and TNF- $\alpha$ levels, which may have contributed to the reduction in IR.
IL-1 $\beta$ can also induce IR by interfering with insulin signaling. Activation of IL-1R induces the secretion and release of other pro-inflammatory cytokines by activating inhibitor of nuclear factor $(\mathrm{NF})-\kappa \mathrm{B}$ kinase $\beta$ subunit and $\mathrm{NF}-\kappa \mathrm{B}$. Inhibitor of $\mathrm{NF}-\kappa \mathrm{B}$ kinase $\beta$ subunit additionally prevents the association of InR and IRS, thereby terminating insulin signaling to PI3K, by phosphorylating IRS-1 at serine 307 (24,57). Furthermore, IL-1 $\beta$ can phosphorylate IRS-1 serine 307 through the activation of c-Jun N-terminal kinases (33), increase the expression of suppressor of cytokine signaling (SOCS) (58), thereby inhibiting insulin receptor-mediated tyrosine phosphorylation of IRS, and promote IRS-1/2 degradation through the competitive tyrosine phosphorylation of insulin receptor tyrosine 960 (59). IL-1 $\beta$ also decreases GLUT4 gene expression, shortens GLUT4 mRNA half-life (60) and reduces transmembrane GLUT4 transport by attenuating Akt activity (61). IL-1 $\beta$ can additionally decrease IRS-1 mRNA levels via the activation of extracellular signaling regulatory kinases (62), and may phosphorylate serine 24 of the IRS-1 pleckstrin homology domain to reduce its tyrosine phosphorylation (63). The increase in serum IL-1 $\beta$ levels observed in control GK rats was markedly inhibited by NCPB in the current study, possibly contributing to the reduced IR observed in the NCPB-treated GK rats. IL-6 has previously been reported to reduce insulin receptor expression, IRS expression, IRS tyrosine phosphorylation, Akt activation and GLUT4 expression $(64,65)$ and to induce SOCS expression through the Janus kinase/Signal Transducer and Activator of Transcription signaling pathway to suppress insulin signaling. Similarly to IL- $1 \beta$ and TNF- $\alpha$, serum levels of IL-6 were significantly decreased following NCPB in the present study, which may have contributed to the alleviation of IR.

Serum FFAs may interfere with multiple aspects of insulin signaling. In a previous study using transgenic mice, elevated FFAs reduced IRS-2 expression, IRS-2 phosphorylation, PI3K activity and GLUT2 expression in liver cells (66); the reduction in IR resulting from NCPB treatments observed in the present study may therefore have resulted in part from reduced serum FFA levels.

The analgesic effect of NCPB is hypothesized to depend on a reduction in the response of the sympathetic nervous system and inhibition of catecholamine release. These effects may also be involved in the reduction of serum FFA and inflammatory cytokine secretion, although this requires additional study. Whilst the mechanisms behind NCPB have yet to be elucidated, it is evident that NCPB can attenuate IR in GK rats by improving insulin signaling and enhancing glucose uptake, suggesting that NCPB may be a feasible treatment for NIDDM. Clinical studies are necessary to test the efficacy of this potential therapeutic in patients with NIDDM.

\section{Acknowledgements}

This study was funded by the Open Foundation of Development and Regeneration Key Laboratory of Sichuan Province (grant no. 12z058), the Hospital Foundation of General Hospital of Chengdu Military Command Area (grant no. 2013YG-B010) and the National Natural Science Foundation of China (grant no. $81171869 / \mathrm{H} 2101$ ). 


\section{References}

1. Chen L, Magliano DJ and Zimmet PZ: The worldwide epidemiology of type 2 diabetes mellitus - present and future perspectives. Nat Rev Endocrinol 8: 228-236, 2011.

2. Brunetti A, Chiefari E and Foti D: Recent advances in the molecular genetics of type 2 diabetes mellitus. World J Diabetes 5: 128-140, 2014.

3. Montane J, Cadavez L and Novials A: Stress and the inflammatory process: A major cause of pancreatic cell death in type 2 diabetes. Diabetes Metab Syndr Obes 7: 25-34, 2014.

4. Mandrup-Poulsen T: Type 2 diabetes mellitus: A metabolic autoinflammatory disease. Dermatol Clin 31: 495-506, 2013.

5. Eguchi K and Manabe I: Macrophages and islet inflammation in type 2 diabetes. Diabetes Obes Metab 15 (Suppl 3): 152-158, 2013

6. Richardson VR, Smith KA and Carter AM: Adipose tissue inflammation: Feeding the development of type 2 diabetes mellitus. Immunobiology 218: 1497-1504, 2013.

7. Mackenzie RW and Elliott BT: Akt/PKB activation and insulin signaling: A novel insulin signaling pathway in the treatment of type 2 diabetes. Diabetes Metab Syndr Obes 7: 55-64, 2014.

8. McPhee JB and Schertzer JD: Immunometabolism of obesity and diabetes: Microbiota link compartmentalized immunity in the gut tometabolic tissue inflammation. Clin Sci (Lond) 129: 1083-1096, 2015.

9. Tanti JF, Ceppo F, Jager J and Berthou F: Implication of inflammatory signaling pathways in obesity-induced insulin resistance. Front Endocrinol (Lausanne) 8: 181, 2013.

10. Jaiswal N, Gunaganti N, Maurya CK, Narender T and Tamrakar AK : Free fatty acid induced impairment of insulin signaling is prevented by the diastereomeric mixture of calophyllic acid and isocalophyllic acid in skeletal muscle cells. Eur J Pharmacol 746: 70-77, 2015.

11. Luo C, Yang H, Tang C, Yao G, Kong L, He H and Zhou Y: Kaempferol alleviates insulin resistance via hepatic IKK/NF- $\kappa \mathrm{B}$ signal in type 2 diabetic rats. Int Immunopharmacol 28: 744-750, 2015.

12. McCall KD, Holliday D, Dickerson E, Wallace B, Schwartz AL, Schwartz C, Lewis CJ, Kohn LD and Schwartz FL: Phenylmethimazole blocks palmitate-mediated induction of inflammatory cytokine pathways in 3T3L1 adipocytes and RAW 264.7 macrophages. J Endocrinol 207: 343-353, 2010.

13. Yang FR, Wu BS, Lai GH, Wang Q, Yang LQ, He MW and Ni JX Assessment of consecutive neurolytic celiac plexus block (NCPB) technique outcomes in the management of refractory visceral cancer pain. Pain Med 13: 518-521, 2012.

14. Li J, Wei XH, Lin L, Che JX, Qiu QM, Zuo HT, An H, Liu YH, Bai SR and Tian FZ: Effect of neurolytic celiac plexus block on insulin resistance after partial hepatectomy in rats. Zhongguo Ji Jiu Yi Xue 33: 1124-1126, 2013 (In Chinese)

15. Akash MS, Rehman K and Chen S: Goto-Kakizaki rats: Its suitability as non-obese diabetic animal model for spontaneous type 2 diabetes mellitus. Curr Diabetes Rev 9: 387-396, 2013.

16. Portha B, Giroix MH,Tourrel-Cuzin C, Le-StunffH and Movassat J: The GK rat: A prototype for the study of non-overweight type 2 diabetes. Methods Mol Biol 933: 125-159, 2012.

17. Chen R, Wang L, Cao HW, Tang CW, Bai XZ and Ji QH: Expression of GLP-1 receptor mRNA in intestine and pancreas of diabetic rats. Di 4 Jun Yi Da Xue Xue Bao 29: 1235-1238, 2008 (In Chinese).

18. Li J, Yan HT, Che JX, Bai SR, Qiu QM, Ren L, Pan F, Sun XQ, Tian FZ, Li DX and Tang LJ: Effects of neurolytic celiac plexus block on liver regeneration in rats with partial hepatectomy. PLoS One 8: e73101, 2013.

19. Wincey $\mathrm{C}$ and Marks V: A micro-method for measuring glucose using the autoanalyzer and glucose-oxidase. J Clin Pathol 14: 558-559, 1961

20. Banerji MA, Chaiken RL, Gordon D, Kral JG and Lebovitz HE: Does intra-abdominal adipose tissue in black men determine whether NIDDM is insulin-resistant or insulin-sensitive? Diabetes 44: 141-146, 1995.

21. Ellis L, Clauser E, Morgan DO, Edery M, Roth RA and Rutter WJ: Replacement of insulin receptor tyrosine residues 1162 and 1163 compromises insulin-stimulated kinase activity and uptake of 2-deoxyglucose. Cell 45: 721-732, 1986.

22. Cherqui G, Reynet C, Caron M, Melin B, Wicek D, Clauser E, Capeau J and Picard J: Insulin receptor tyrosine residues 1162 and 1163 control insulin stimulation of myristoyl-diacylglycerol generation and subsequent activation of glucose transport. J Biol Chem 265: 21254-21261, 1990.
23. Virkamäki A, Ueki K and Kahn CR: Protein-protein interaction in insulin signaling and the molecular mechanisms of insulin resistance. J Clin Invest 103: 931-943, 1999.

24. Aguirre V, Werner ED, Giraud J, Lee YH, Shoelson SE and White MF: Phosphorylation of Ser307 in insulin receptor substrate-1 blocks interactions with the insulin receptor and inhibits insulin action. J Biol Chem 277: 1531-1537, 2002.

25. Hsueh WA and Buchanan TA: Obesity and hypertension. Endocrinol Metab Clin North Am 23: 405-427, 1994.

26. Elmendorf JS, Damrau-Abney A, Smith TR, David TS and Turinsky J: Phosphatidylinositol 3-kinase and dynamics of insulin resistance in denervated slow and fast muscles in vivo. Am J Physiol 272: E661-E670, 1997.

27. Lee J and Pilch PF: The insulin receptor: Structure, function and signaling. Am J Physiol 266: C319-C334, 1994

28. Kobayashi M, Iwanishi M, Egawa K and Shigeta Y: Pioglitazone increases insulin sensitivity by activating insulin receptor kinase. Diabetes 41: 476-483, 1992

29. Ola MS: Effect of hyperglycemia on insulin receptor signaling in the cultured retinal Müller glial cells. Biochem Biophys Res Commun 444: 264-269, 2014

30. Fasshauer M, Klein J, Kriauciunas KM, Ueki K, Benito M and Kahn CR: Essential role of insulin receptor substrate 1 in differentiation of brown adipocytes. Mol Cell Biol 21: 319-329, 2001.

31. Lehr S, Kotzka J, Herkner A, Sikmann A, Meyer HE, Krone W and Müller-Wieland D: Identification of major tyrosine phosphorylation sites in the human insulin receptor substrate Gab-1 by insulin receptor kinase in vitro. Biochemistry 39: 10898-10907, 2000.

32. Hotamisligil GS, Peraldi P, Budavari A, Ellis R, White MF and Spiegelman BM: IRS-1-mediated inhibition of insulin receptor tyrosine kinase activity in TNF-alpha- and obesity-induced insulin resistance. Science 271: 665-668, 1996.

33. Aguirre V, Uchida T, Yenush L, Davis R and White MF: The c-Jun $\mathrm{NH}(2)$-terminal kinase promotes insulin resistance during association with insulin receptor substrate-1 and phosphorylation of Ser (307). J Biol Chem 275: 9047-9054, 2000.

34. Anderson KE, Coadwell J, Stephens LR and Hawkins PT: Translocation of PDK-1 to the plasma membrane is important in allowing PDK-1 to activate protein kinase B. Curr Biol 8: 684-691, 1998

35. Cao S, Li B, Yi X, Chang B, Zhu B, Lian Z, Zhang Z, Zhao G, Liu $\mathrm{H}$ and $\mathrm{Zhang} \mathrm{H}$ : Effects of exercise on AMPK signaling and downstream components to PI3K in rat with type 2 diabetes. PLoS One 7: e51709, 2012.

36. He L, Simmen FA, Mehendale HM, Ronis MJ and Badger TM: Chronic ethanol intake impairs insulin signaling in rats by disrupting Akt association with the cell membrane. Role of TRB3 in inhibition of Akt/protein kinase B activation. J Biol Chem 281: 11126-11134, 2006.

37. Rea S and James DE: Moving GLUT4: The biogenesis and trafficking of GLUT4 storage vesicles. Diabetes 46: 1667-1677, 1997.

38. Mueckler M: Facilitative glucose transporters. Eur J Biochem 219 713-725, 1994

39. Mueckler M, Caruso C, Baldwin SA, Panico M, Blench I, Morris HR, Allard WJ, Lienhard GE and Lodish HF: Sequence and structure of a human glucose transporter. Science 229: 941-945, 1985.

40. Kahn BB: Facilitative glucose transporters: Regulatory mechanisms and dysregulation in diabetes. J Clin Invest 89: 1367-1374, 1992.

41. Garvey WT, Maianu L, Huecksteadt TP, Birnbaum MJ, Molina JM and Ciaraldi TP: Pretranslational suppression of a glucose transporter protein causes insulin resistance in adipocytes from patients with non-insulin-dependent diabetes mellitus and obesity. J Clin Invest 87: 1072-1081, 1991.

42. Kelley DE, Mintun MA, Watkins SC, Simoneau JA, Jadali F, Fredrickson A, Beattie J and Thériault R: The effect of non-insulin-dependent diabetes mellitus and obesity on glucose transport and phosphorylation in skeletal muscle. J Clin Invest 97: 2705-2713, 1996

43. Calle MC and Fernandez ML: Inflammation and type 2 diabetes. Diabetes Metab 38: 183-191, 2012.

44. Donath MY: Inflammation as a sensor of metabolic stress in obesity and type 2 diabetes. Endocrinology 152: 4005-4006, 2011.

45. Borst SE: The role of TNF-alpha in insulin resistance. Endocrine 23: 177-182, 2004

46. Qi C and Pekala PH: Tumor necrosis factor-alpha-induced insulin resistance in adipocytes. Proc Soc Exp Biol Med 223: $128-135,2000$ 
47. Kanety H, Feinstein R, Papa MZ, Hemi R and Karasik A Tumor necrosis factor alpha-induced phosphorylation of insulin receptor substrate-1 (IRS-1). Possible mechanism for suppression of insulin-stimulated tyrosine phosphorylation of IRS-1. J Biol Chem 270: 23780-23784, 1995.

48. Paz K, Hemi R, LeRoith D, Karasik A, Elhanany E, Kanety H and Zick Y: A molecular basis for insulin resistance. Elevated serine/threonine phosphorylation of IRS-1 and IRS-2 inhibits their binding to the juxtamembrane region of the insulin receptor and impairs their ability to undergo insulin-induced tyrosine phosphorylation. J Biol Chem 272: 29911-29918, 1997.

49. Heydrick SJ, Jullien D, Gautier N, Tanti JF, Giorgetti S Van Obberghen E and Le Marchand-Brustel Y: Defect in skeletal muscle phosphatidylinositol-3-kinase in obese insulin-resistant mice. J Clin Invest 91: 1358-1366, 1993.

50. Stephens JM, Lee J and Pilch PF: Tumor necrosis factor-alpha-induced insulin resistance in 3T3-L1 adipocytes is accompanied by a loss of insulin receptor substrate- 1 and GLUT4 expression without a loss of insulin receptor-mediated signal transduction. J Biol Chem 272: 971-976, 1997.

51. Wang CN, O'Brien L and Brindley DN: Effects of cell-permeable ceramides and tumor necrosis factor-alpha on insulin signaling and glucose uptake in 3T3-L1 adipocytes. Diabetes 47: 24-31, 1998.

52. Hauner H, Petruschke T, Russ M, Röhrig K and Eckel J: Effects of tumour necrosis factor alpha (TNF alpha) on glucose transport and lipid metabolism of newly-differentiated human fat cells in cell culture. Diabetologia 38: 764-771, 1995.

53. Miles PD, Romeo OM, Higo K, Cohen A, Rafaat K and Olefsky JM: TNF-alpha-induced insulin resistance in vivo and its prevention by troglitazone. Diabetes 46: 1678-1683, 1997.

54. Lang CH, Dobrescu C and Bagby GJ: Tumor necrosis factor impairs insulin action on peripheral glucose disposal and hepatic glucose output. Endocrinology 130: 43-52, 1992.

55. Yu C, Chen Y, Cline GW, Zhang D, Zong H, Wang Y, Bergeron R, Kim JK, Cushman SW, Cooney GJ, et al: Mechanism by which fatty acids inhibit insulin activation of insulin receptor substrate-1 (IRS-1)-associated phosphatidylinositol 3-kinase activity in muscle. J Biol Chem 277: 50230-50236, 2002.

56. Hotamisligil GS and Spiegelman BM: Tumor necrosis factor alpha: A key component of the obesity-diabetes link. Diabetes 43 : 1271-1278, 1994.
57. Takaesu G, Ninomiya-Tsuji J, Kishida S, Li X, Stark GR and Matsumoto K: Interleukin-1 (IL-1) receptor-associated kinase leads to activation of TAK1 by inducing TAB2 translocation in the IL-1 signaling pathway. Mol Cell Biol 21: 2475-2484, 2001.

58. Emanuelli B, Glondu M,Filloux C,Peraldi Pand Van ObberghenE: The potential role of SOCS-3 in the interleukin-1beta-induced desensitization of insulin signaling in pancreatic beta-cells Diabetes 53 (Suppl 3): S97-S103, 2004.

59. Rui L, Yuan M, Frantz D, Shoelson S and White MF: SOCS-1 and SOCS-3 block insulin signaling by ubiquitin-mediated degradation of IRS1 and IRS2. J Biol Chem 277: 42394-42398, 2002.

60. Fujishiro M, Gotoh Y, Katagiri H, Sakoda H, Ogihara T, Anai M, Onishi Y, Ono H, Funaki M, Inukai K, et al: MKK6/3 and p38 MAPK pathway activation is not necessary for insulin-induced glucose uptake but regulates glucose transporter expression. J Biol Chem 276: 19800-19806, 2001.

61. Eguez L, Lee A, Chavez JA, Miinea CP, Kane S, Lienhard GE and McGraw TE: Full intracellular retention of GLUT4 requires AS160 Rab GTPase activating protein. Cell Metab 2: 263-272, 2005.

62. Jager J, Grémeaux T, Cormont M, Le Marchand-Brustel Y and Tanti JF: Interleukin-1beta-induced insulin resistance in adipocytes through down-regulation of insulin receptor substrate-1 expression. Endocrinology 148: 241-251, 2007.

63. Kim JA, Yeh DC, Ver M, Li Y, Carranza A, Conrads TP, Veenstra TD, Harrington MA and Quon MJ: Phosphorylation of Ser24 in the pleckstrin homology domain of insulin receptor substrate-1 by Mouse Pelle-like kinase/interleukin-1 receptor-associated kinase: Cross-talk between inflammatory signaling and insulin signaling that may contribute to insulin resistance. J Biol Chem 280: 23173-23183, 2005.

64. Lagathu C, Bastard JP, Auclair M, Maachi M, Capeau J and Caron M: Chronic interleukin-6 (IL-6) treatment increased IL-6 secretion and induced insulin resistance in adipocyte: Prevention by rosiglitazone. Biochem Biophys Res Commun 311: 372-379, 2003.

65. Senn JJ, Klover PJ, Nowak IA and Mooney RA: Interleukin-6 induces cellular insulin resistance in hepatocytes. Diabetes 51: 3391-3399, 2002

66. Sun Y, Liu S, Ferguson S, Wang L, Klepcyk P, Yun JS and Friedman JE: Phosphoenolpyruvate carboxykinase overexpression selectively attenuates insulin signaling and hepatic insulin sensitivity in transgenic mice. J Biol Chem 277: 23301-23307, 2002. 